\title{
Supramolecular Templating Approach for the Solvent-Free Synthesis of Open-Framework Metal Oxalates
}

\author{
Furong Guo, ${ }^{\dagger, \star}$ Cheng Chen, ${ }^{\dagger, \star}$ Kangcai Wang, ${ }^{\S}$ Qinghua Zhang, ${ }^{*}{ }^{\S}$ and Zhien Lin $*, \dagger$ \\ ${ }^{+}$College of Chemistry, Sichuan University, Chengdu 610064, P. R. China \\ § Institute of Chemical Materials, China Academy of Engineering Physics, Mianyang \\ 621900, P. R. China \\ $\$$ These authors contributed equally. \\ * To whom correspondence should be addressed. Tel: +86-28-85412284. E-mail: \\ qinghuazhang@caep.cn (Q. Z.); zhienlin@scu.edu.cn (Z. L.)
}




\section{Physical measurements:}

IR spectra ( $\mathrm{KBr}$ pellets) were recorded on a Nicolet Impact 410 FTIR spectrometer. Powder X-ray diffraction (XRD) data were obtained using a Shimadzu XRD-6100 diffractometer with $\mathrm{Cu}-\mathrm{K} \alpha$ radiation $(\lambda=1.5418 \AA)$. The thermogravimetric analyses were performed on a Netzsch STA 449c analyzer in a flow of $\mathrm{N}_{2}$ with a heating rate of $10{ }^{\circ} \mathrm{C} / \mathrm{min}$. Single crystal X-ray diffraction data were collected on a New Gemini, Dual, $\mathrm{Cu}$ at zero, EosS2 diffractometer at room temperature. The crystal structures were solved by direct methods. The structures were refined on $F^{2}$ by full-matrix least-squares methods using the SHELXTL program package. ${ }^{1}$ Ac impedance measurements were carried out with a Zennium/IM6 impedance analyzer over the frequency range from 0.1 $\mathrm{Hz}$ to $5 \mathrm{MHz}$ with an applied voltage of $50 \mathrm{mV}$. The relative humidity was controlled by a STIK Corp. CIHI-150B incubator. The sample was pressed to form a cylindrical pellet of crystalline powder sample $(\sim 2 \mathrm{~mm}$ thickness $\times 5 \mathrm{~mm} \phi)$ coated with C-pressed electrodes. Two silver electrodes were attached to both sides of pellet to form four end terminals (quasi-four-probe method). The bulk conductivity was estimated by semicircle fittings of Nyquist plots.

Reference

1. G. M. Sheldrick, Acta Cryst., Sect. A 2008, 64, 112.

\section{Synthesis}

Synthesis of $\left[\left(\mathbf{H}_{2} \mathbf{d m p}\right)\left(\mathrm{SO}_{4}\right)_{2}\right]\left[\mathrm{Zn}_{3}(\mathbf{O x})_{2}\left(\mathrm{H}_{2} \mathrm{O}\right)_{7}\right]$ (1): A mixture of $\mathrm{ZnSO}_{4} \cdot 7 \mathrm{H}_{2} \mathrm{O}$ (0.575 g), $\mathrm{H}_{2} \mathrm{C}_{2} \mathrm{O}_{4} \cdot 2 \mathrm{H}_{2} \mathrm{O}(0.126 \mathrm{~g})$, and 1,4-dimethylpiperazine (135 $\left.\mu \mathrm{l}\right)$ was sealed in a Teflon-lined stainless steel autoclave and heated at $150{ }^{\circ} \mathrm{C}$ for 7 days. The autoclave 
was subsequently allowed to cool to room temperature. Colorless crystals were recovered by filtration, washed with methanol, and finally dried at ambient temperature (46.1\% yield based on zinc).

Synthesis of $\left[\left(\mathbf{H}_{2} \mathbf{d m p}\right)\left(\mathbf{S O}_{4}\right)_{2}\right]\left[\mathbf{C o}_{3}(\mathbf{o x})_{2}\left(\mathbf{H}_{2} \mathbf{O}\right)_{7}\right](\mathbf{2})$ : A mixture of $\mathrm{CoSO}_{4} \cdot 7 \mathrm{H}_{2} \mathrm{O}(0.562$ g), $\mathrm{H}_{2} \mathrm{C}_{2} \mathrm{O}_{4} \cdot 2 \mathrm{H}_{2} \mathrm{O}(0.126 \mathrm{~g})$, and 1,4-dimethylpiperazine $(135 \mu \mathrm{L})$ was sealed in a Teflon-lined stainless steel autoclave and heated at $150{ }^{\circ} \mathrm{C}$ for $7 \mathrm{~d}$. The autoclave was subsequently allowed to cool to room temperature. Violet crystals were recovered by filtration, washed with distilled water, and finally dried at ambient temperature $(22.8 \%$ yield based on cobalt).

Synthesis of $\left[(\mathbf{H d p a})_{4}(\mathbf{o x})\right]\left[\mathbf{M n}_{\mathbf{2}}(\mathbf{o x})_{3}\right]$ (3): A mixture of $\mathrm{MnO}(0.150 \mathrm{~g}), \mathrm{H}_{2} \mathrm{C}_{2} \mathrm{O}_{4} \cdot 2 \mathrm{H}_{2} \mathrm{O}$ $(0.504 \mathrm{~g})$, and diisopropylamine $(570 \mu \mathrm{l})$ was sealed in a Teflon-lined stainless steel autoclave and heated at $150{ }^{\circ} \mathrm{C}$ for 7 days. The autoclave was subsequently allowed to cool to room temperature. Light pink crystals were recovered by filtration, washed with DMF and ethanol, and finally dried at ambient temperature $(25.6 \%$ yield based on manganese).

Synthesis of $\left[\left(\mathrm{H}_{2} \mathbf{d a p}\right)(\mathbf{H o x})\right]\left[\mathrm{Bi}_{2}(\mathbf{o x})_{3.5}\left(\mathbf{H}_{2} \mathbf{O}\right)\right] \cdot \mathbf{H}_{2} \mathrm{O}(4)$ : A mixture of $\mathrm{Bi}_{2} \mathrm{O}_{3}(0.233 \mathrm{~g})$, $\mathrm{H}_{2} \mathrm{C}_{2} \mathrm{O}_{4} \cdot 2 \mathrm{H}_{2} \mathrm{O}(0.441 \mathrm{~g})$, and 1,2-diaminopropane (43 $\left.\mu \mathrm{L}\right)$ was sealed in a Teflon-lined stainless steel autoclave and heated at $120{ }^{\circ} \mathrm{C}$ for $4 \mathrm{~d}$. The autoclave was subsequently allowed to cool to room temperature. Colorless crystals were recovered by filtration, washed with distilled water, and finally dried at ambient temperature $(40.6 \%$ yield based on bismuch).

Synthesis of $\left[\left(\mathrm{H}_{2} \mathbf{e p i p}\right)\left(\mathbf{S O}_{4}\right)\right]\left[\operatorname{In}(\mathbf{o x})_{1.5}\right] \quad(5)$ : A mixture of $\operatorname{In}(\mathrm{OH})_{3} \quad(0.165 \mathrm{~g})$, $\mathrm{H}_{2} \mathrm{C}_{2} \mathrm{O}_{4} \cdot 2 \mathrm{H}_{2} \mathrm{O}(0.189 \mathrm{~g}), \mathrm{H}_{2} \mathrm{SO}_{4}(98 \mathrm{wt} \%, 54 \mu \mathrm{L})$, and 1-ethylpiperazine (130 $\left.\mu \mathrm{L}\right)$ was sealed in a Teflon-lined stainless steel autoclave and heated at $150{ }^{\circ} \mathrm{C}$ for $5 \mathrm{~d}$. The 
autoclave was subsequently allowed to cool to room temperature. Colorless crystals were recovered by filtration, washed with ethanol, and finally dried at ambient temperature (60.3\% yield based on indium).

Synthesis of $\left[\left(\mathbf{H}_{2} \mathbf{e p i p}\right)(\mathbf{o x})\right]\left[\operatorname{In}(\mathbf{o x})_{1.5}\right] \quad(\mathbf{6}):$ A mixture of $\operatorname{In}(\mathrm{OH})_{3} \quad(0.166 \mathrm{~g})$, $\mathrm{H}_{2} \mathrm{C}_{2} \mathrm{O}_{4} \cdot 2 \mathrm{H}_{2} \mathrm{O}(0.378 \mathrm{~g})$, and 1-ethylpiperazine $(130 \mu \mathrm{L})$ was sealed in a Teflon-lined stainless steel autoclave and heated at $150{ }^{\circ} \mathrm{C}$ for $5 \mathrm{~d}$. The autoclave was subsequently allowed to cool to room temperature. Colorless crystals were recovered by filtration, washed with distilled water, and finally dried at ambient temperature $(67.4 \%$ yield based on indium).

Table S1. Hydrogen bonds for compound 1

\begin{tabular}{lllll}
\hline $\mathrm{D}-\mathrm{H} \cdots \mathrm{A}^{\mathrm{a}}$ & $\mathrm{d}(\mathrm{D}-\mathrm{H})(\AA)$ & $\mathrm{d}(\mathrm{H} \cdots \mathrm{A})(\AA)$ & $\mathrm{d}(\mathrm{D} \cdots \mathrm{A})(\AA)$ & $<(\mathrm{DHA})(\mathrm{deg})$ \\
\hline $\mathrm{N} 1-\mathrm{H} 1 \cdots \mathrm{O} 9 \# 1$ & 0.98 & 2.38 & $3.178(5)$ & 137.7 \\
$\mathrm{~N} 1-\mathrm{H} 1 \cdots \mathrm{O} 12 \# 1$ & 0.98 & 2.11 & $3.022(4)$ & 153.1 \\
\hline
\end{tabular}

${ }^{a}$ Symmetry transformations used to generate equivalent atoms: \#1 1/2+x+1, +y, 1/2-z.

Table S2. Hydrogen bonds for compound 2

\begin{tabular}{lllll}
\hline $\mathrm{D}-\mathrm{H} \cdots \mathrm{A}^{\mathrm{a}}$ & $\mathrm{d}(\mathrm{D}-\mathrm{H})(\AA)$ & $\mathrm{d}(\mathrm{H} \cdots \mathrm{A})(\AA)$ & $\mathrm{d}(\mathrm{D} \cdots \mathrm{A})(\AA)$ & $<(\mathrm{DHA})(\mathrm{deg})$ \\
\hline $\mathrm{N} 1-\mathrm{H} 1 \cdots \mathrm{O} 9 \# 1$ & 0.98 & 2.39 & $3.191(11)$ & 138.8 \\
$\mathrm{~N} 1-\mathrm{H} 1 \cdots \mathrm{O} 12 \# 1$ & 0.98 & 2.13 & $3.027(10)$ & 151.8 \\
\hline
\end{tabular}

${ }^{a}$ Symmetry transformations used to generate equivalent atoms: \#1 1/2+x+1, +y, 1/2-z. 
Table S3. Hydrogen bonds for compound 3

\begin{tabular}{lllll}
\hline $\mathrm{D}-\mathrm{H} \cdots \mathrm{A}^{\mathrm{a}}$ & $\mathrm{d}(\mathrm{D}-\mathrm{H})(\AA)$ & $\mathrm{d}(\mathrm{H} \cdots \mathrm{A})(\AA)$ & $\mathrm{d}(\mathrm{D} \cdots \mathrm{A})(\AA)$ & $<(\mathrm{DHA})(\mathrm{deg})$ \\
\hline $\mathrm{N} 1-\mathrm{H} 1 \mathrm{~A} \cdots \mathrm{O} 7 \# 1$ & 0.89 & 2.29 & $2.880(3)$ & 123.5 \\
$\mathrm{~N} 1-\mathrm{H} 1 \mathrm{~A} \cdots \mathrm{O} 8 \# 2$ & 0.89 & 1.90 & $2.739(3)$ & 156.9 \\
$\mathrm{~N} 2-\mathrm{H} 2 \mathrm{~A} \cdots \mathrm{O} 7$ & 0.89 & 1.84 & $2.717(3)$ & 168.9 \\
\hline
\end{tabular}

${ }^{a}$ Symmetry transformations used to generate equivalent atoms: \#1 -x, 1-y, -z; \#2 -1+x, $+\mathrm{y},+\mathrm{z}$.

Table S4. Hydrogen bonds for compound 4

\begin{tabular}{llllc}
\hline D-H $\cdots \mathrm{A}^{\mathrm{a}}$ & $\mathrm{d}(\mathrm{D}-\mathrm{H})(\AA)$ & $\mathrm{d}(\mathrm{H} \cdots \mathrm{A})(\AA)$ & $\mathrm{d}(\mathrm{D} \cdots \mathrm{A})(\AA)$ & $<(\mathrm{DHA})(\mathrm{deg})$ \\
\hline $\mathrm{N} 1-\mathrm{H} 1 \mathrm{~B} \cdots \mathrm{O} 16 \# 1$ & 0.89 & 2.07 & $2.863(8)$ & 148.0 \\
$\mathrm{~N} 1-\mathrm{H} 1 \mathrm{C} \cdots \mathrm{O} 15 \# 2$ & 0.89 & 1.89 & $2.776(7)$ & 172.0 \\
$\mathrm{~N} 2-\mathrm{H} 2 \mathrm{~A} \cdots \mathrm{O} 15 \# 2$ & 0.89 & 1.95 & $2.807(7)$ & 161.2 \\
\hline
\end{tabular}

${ }^{a}$ Symmetry transformations used to generate equivalent atoms: \#1 1-x, -1/2+y, 3/2-z; \#2

$1-\mathrm{x}, 1-\mathrm{y}, 1-\mathrm{z}$

Table S5. Hydrogen bonds for compound $\mathbf{5}$

\begin{tabular}{lllll}
\hline $\mathrm{D}-\mathrm{H} \cdots \mathrm{A}^{\mathrm{a}}$ & $\mathrm{d}(\mathrm{D}-\mathrm{H})(\AA)$ & $\mathrm{d}(\mathrm{H} \cdots \mathrm{A})(\AA)$ & $\mathrm{d}(\mathrm{D} \cdots \mathrm{A})(\AA)$ & $<(\mathrm{DHA})(\mathrm{deg})$ \\
\hline $\mathrm{N} 1-\mathrm{H} 1 \cdots \mathrm{O} 10 \# 1$ & 0.98 & 1.93 & $2.907(4)$ & 172.6 \\
& & & \\
& & &
\end{tabular}




\begin{tabular}{llllc} 
N2-H2A $\cdots$ O8\#2 & 0.89 & 2.16 & $2.847(4)$ & 133.3 \\
N2-H2B $\cdots$ O9 & 0.89 & 1.82 & $2.709(4)$ & 173.0 \\
\hline
\end{tabular}

${ }^{a}$ Symmetry transformations used to generate equivalent atoms: \#1

3/4-Y, -1/4+X, 3/4-Z; \#2 3/4-Y, -1/4+X, 7/4-Z.

Table S6. Hydrogen bonds for compound 6

\begin{tabular}{lllll}
\hline $\mathrm{D}-\mathrm{H} \cdots \mathrm{A}^{\mathrm{a}}$ & $\mathrm{d}(\mathrm{D}-\mathrm{H})(\AA)$ & $\mathrm{d}(\mathrm{H} \cdots \mathrm{A})(\AA)$ & $\mathrm{d}(\mathrm{D} \cdots \mathrm{A})(\AA)$ & $<(\mathrm{DHA})(\mathrm{deg})$ \\
\hline $\mathrm{N} 1-\mathrm{H} 1 \cdots \mathrm{O} 8 \# 1$ & 0.98 & 1.95 & $2.908(4)$ & 164.4 \\
$\mathrm{~N} 2-\mathrm{H} 2 \mathrm{~A} \cdots \mathrm{O} 9 \# 2$ & 0.89 & 1.95 & $2.787(4)$ & 155.1 \\
$\mathrm{~N} 2-\mathrm{H} 2 \mathrm{~B} \cdots \mathrm{O} 10$ & 0.89 & 1.82 & $2.683(5)$ & 164.3 \\
\hline
\end{tabular}

${ }^{a}$ Symmetry transformations used to generate equivalent atoms: \#1

3/4-Y, -1/4+X, 3/4-Z; \#2 3/4-Y, -1/4+X, 7/4-Z. 


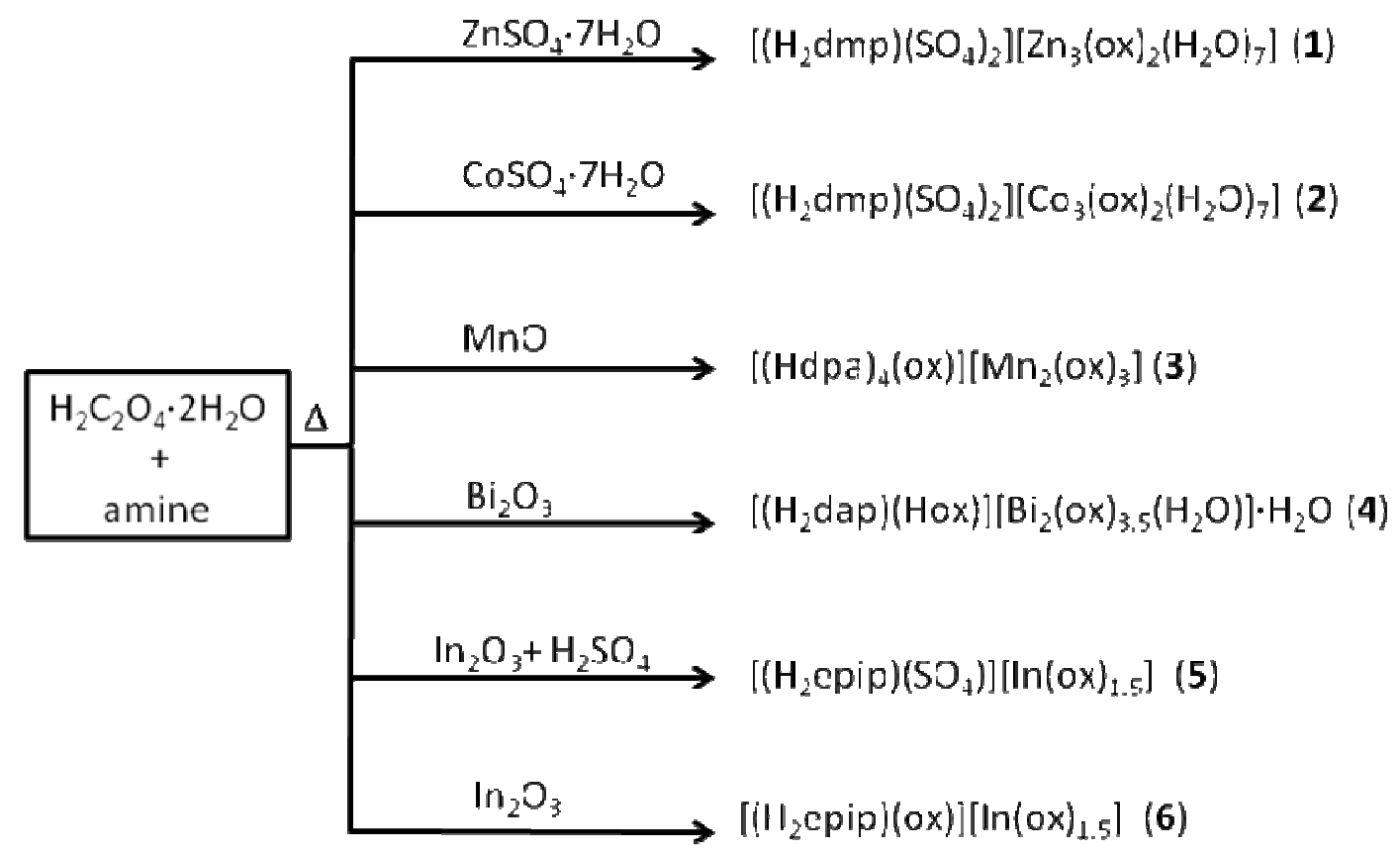

Scheme S1. Schematic illustration of the synthetic conditions of compounds 1-6.

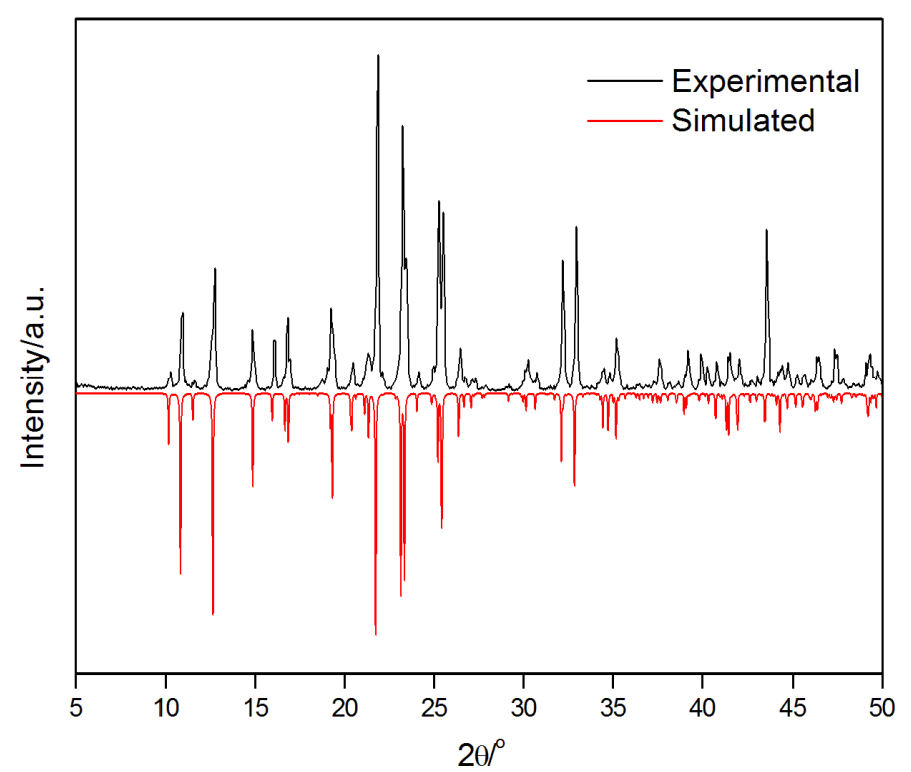

Figure S1. Experimental and simulated powder XRD patterns of compound 1. 


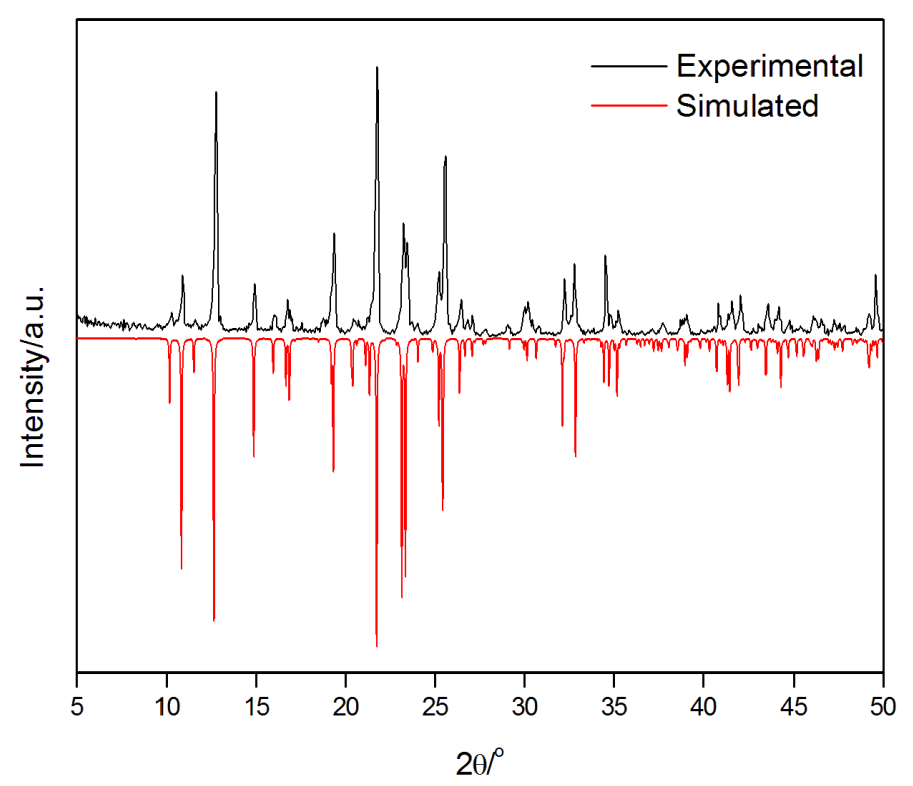

Figure S2. Experimental and simulated powder XRD patterns of compound 2.

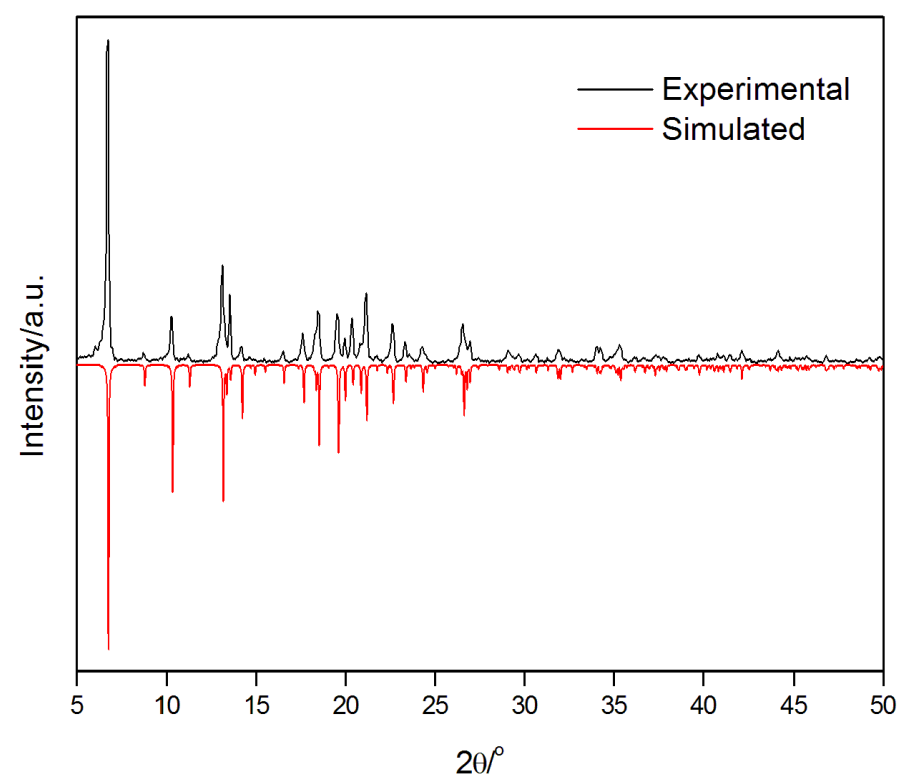

Figure S3. Experimental and simulated powder XRD patterns of compound 3. 


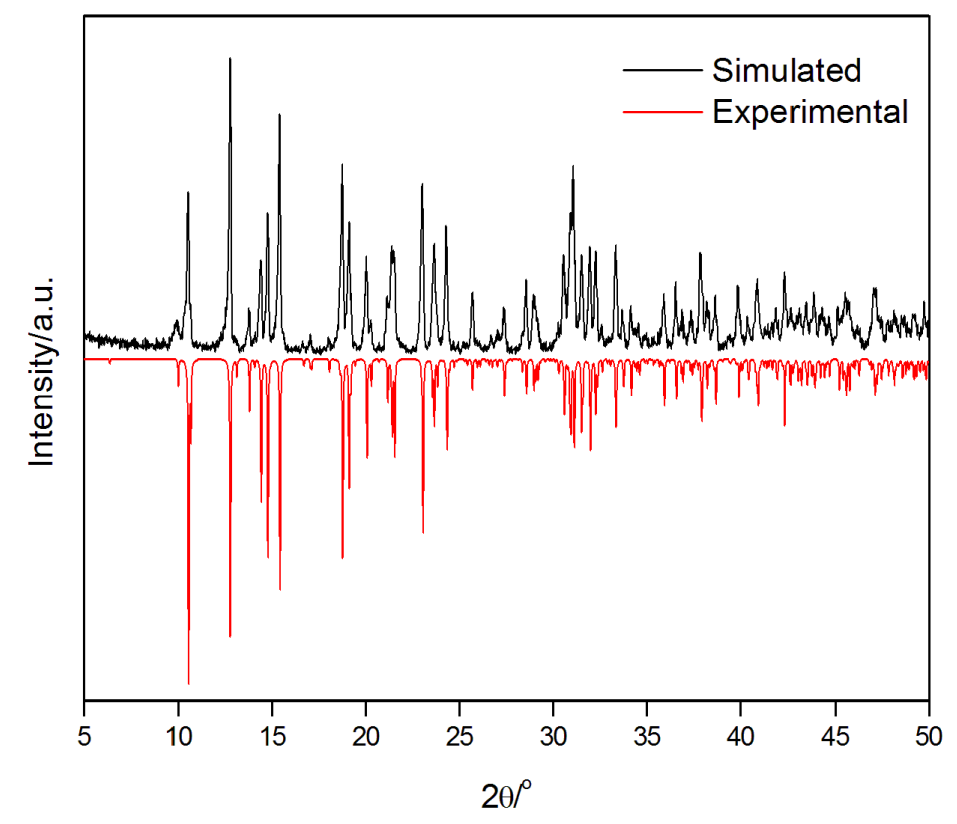

Figure S4. Experimental and simulated powder XRD patterns of compound 4.

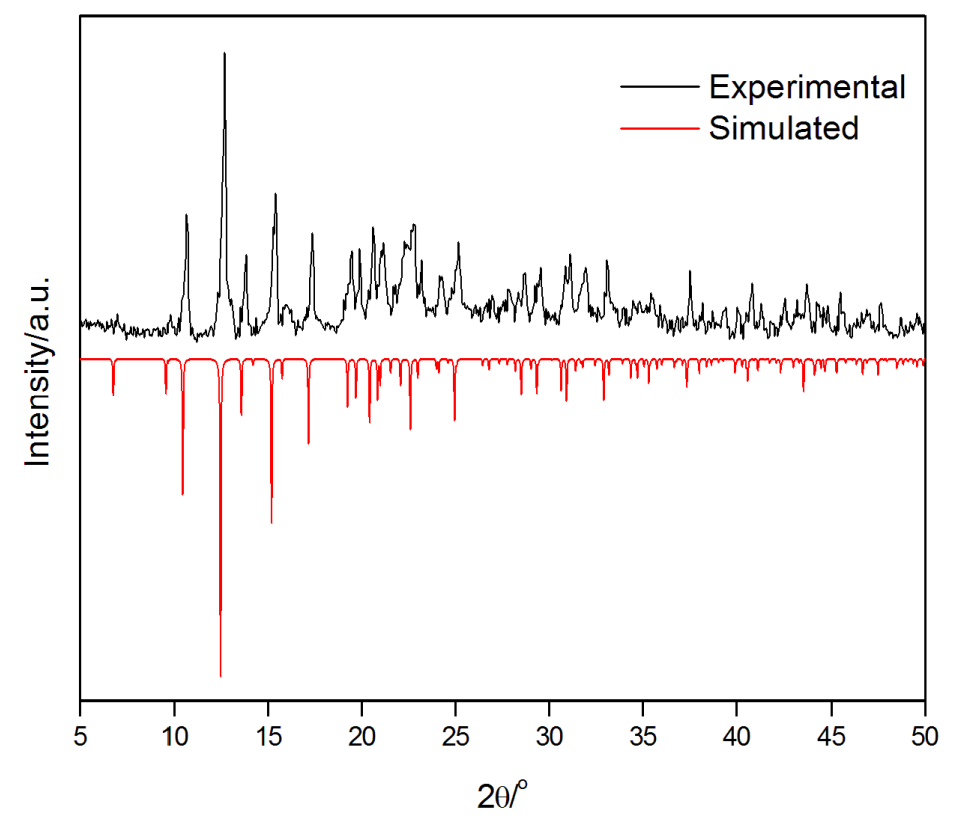

Figure S5. Experimental and simulated powder XRD patterns of compound 5. 


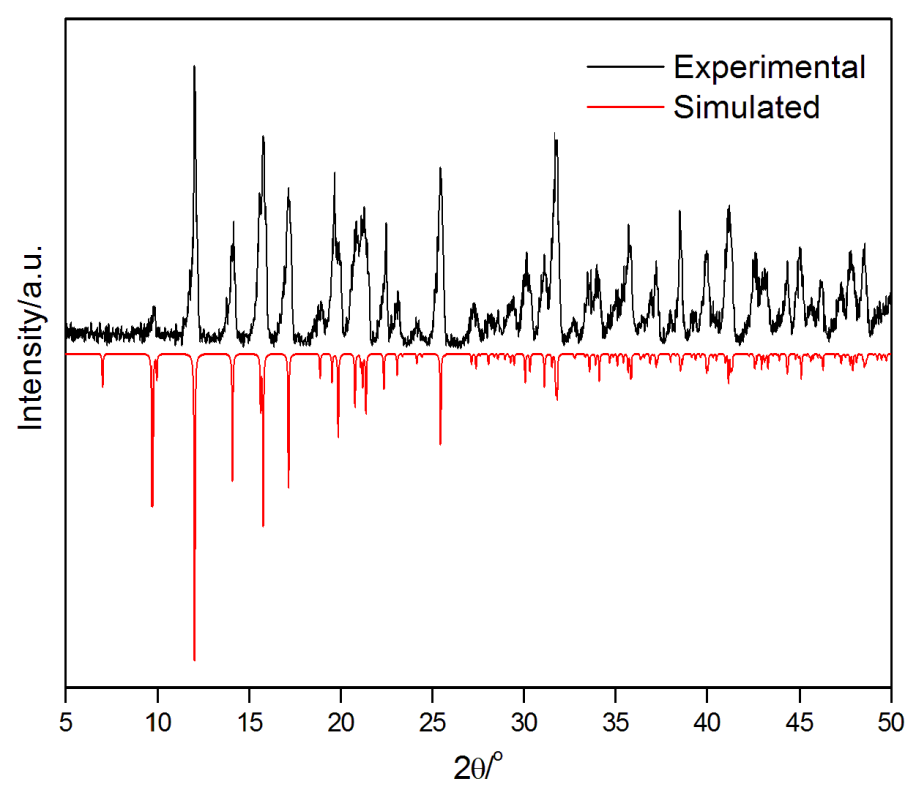

Figure S6. Experimental and simulated powder XRD patterns of compound 6.

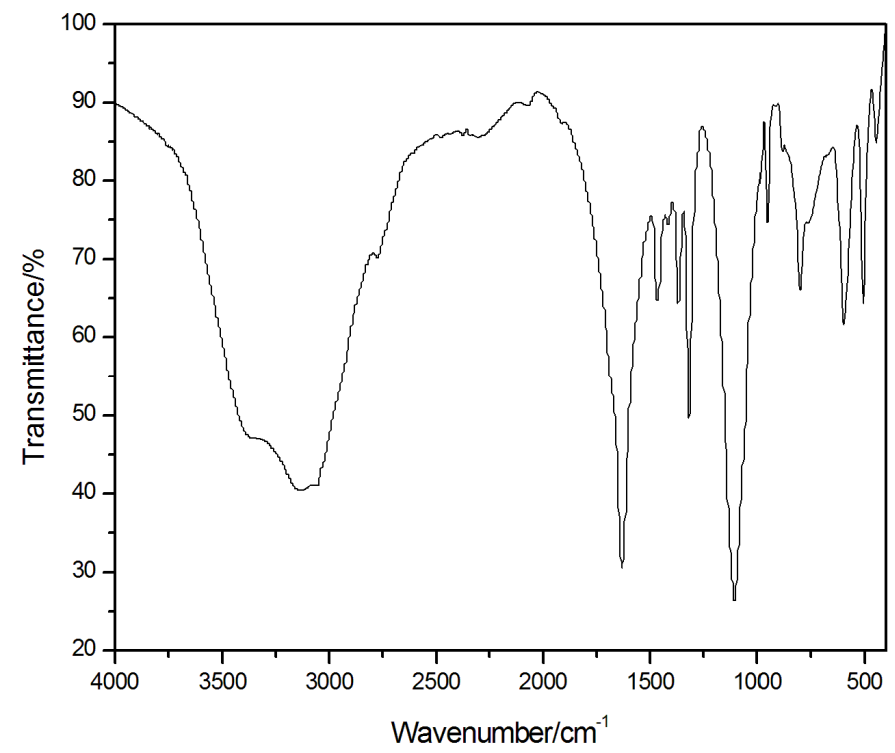

Figure S7. IR spectrum of compound 1. The peaks at $1630 \mathrm{~cm}^{-1}$ and $1320 \mathrm{~cm}^{-1}$ are attributed to the stretching vibrations of $\mathrm{C}=\mathrm{O}$ and $\mathrm{C}-\mathrm{O}$ in oxalate ligands. The intense bands at $1100 \mathrm{~cm}^{-1}$ is associated with the stretching vibrations of $\mathrm{SO}_{4}$ groups. The bands at 1460 and $1370 \mathrm{~cm}^{-1}$ are caused by the $\mathrm{C}-\mathrm{H}$ scissoring and bending vibrations. 


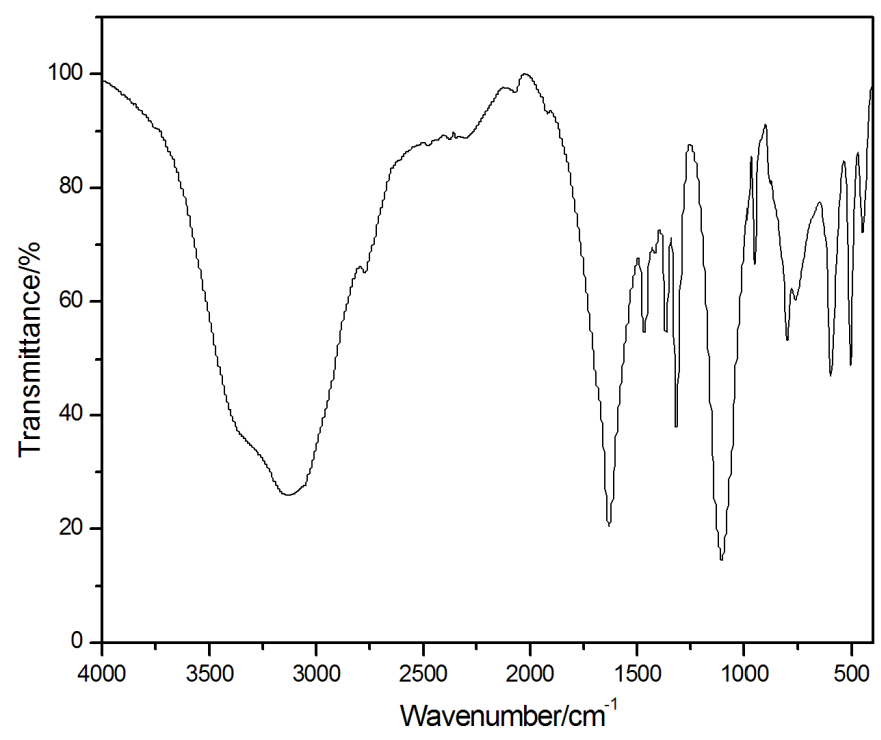

Figure S8. IR spectrum of compound 2. The peaks at $1630 \mathrm{~cm}^{-1}$ and $1320 \mathrm{~cm}^{-1}$ are attributed to the stretching vibrations of $\mathrm{C}=\mathrm{O}$ and $\mathrm{C}-\mathrm{O}$ in oxalate ligands. The intense bands at $1100 \mathrm{~cm}^{-1}$ is associated with the stretching vibrations of $\mathrm{SO}_{4}$ groups. The bands at 1460 and $1360 \mathrm{~cm}^{-1}$ are caused by the $\mathrm{C}-\mathrm{H}$ scissoring and bending vibrations.

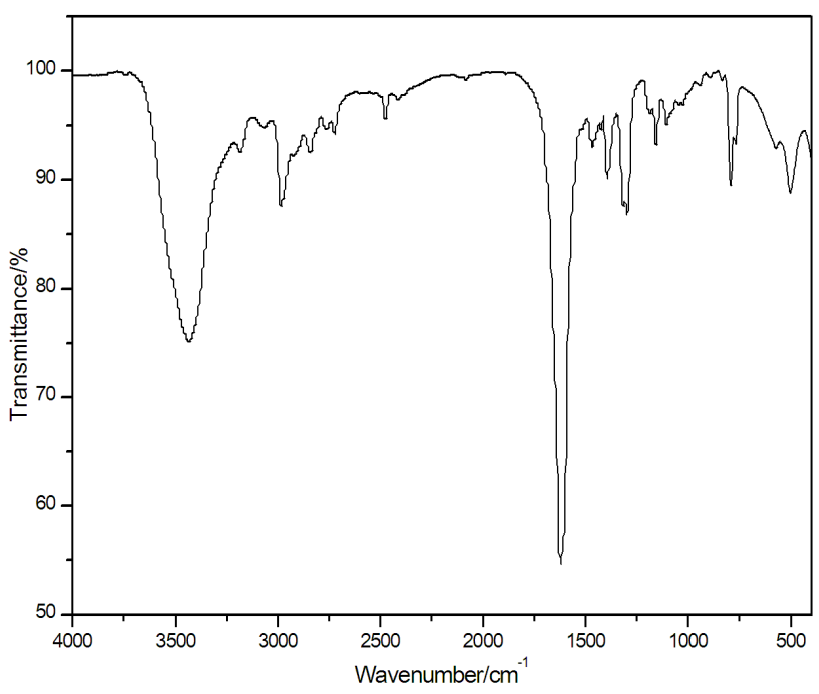

Figure S9. IR spectrum of compound 3. The peaks at $1620 \mathrm{~cm}^{-1}$ and $1300 \mathrm{~cm}^{-1}$ are attributed to the stretching vibrations of $\mathrm{C}=\mathrm{O}$ and $\mathrm{C}-\mathrm{O}$ in oxalate ligands. The bands at 2980, 1470, and $1390 \mathrm{~cm}^{-1}$ are caused by the $\mathrm{C}-\mathrm{H}$ stretching, scissoring, and bending vibrations. The band at $3430 \mathrm{~cm}^{-1}$ is associated with the $\mathrm{N}-\mathrm{H}$ stretching vibrations. 


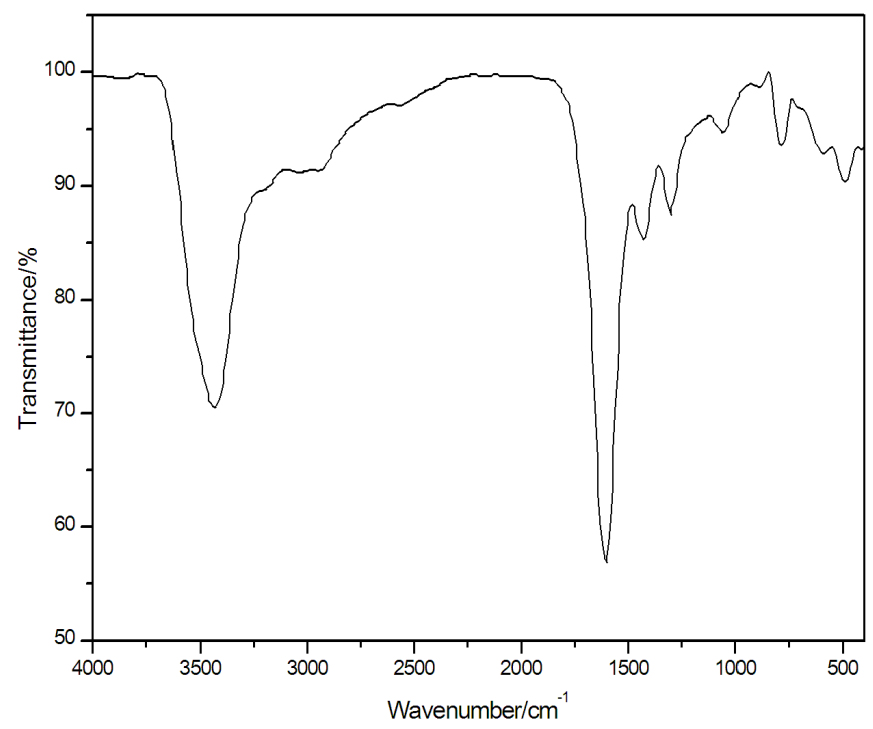

Figure S10. IR spectrum of compound 4. The peaks at $1600 \mathrm{~cm}^{-1}$ and $1300 \mathrm{~cm}^{-1}$ are attributed to the stretching vibrations of $\mathrm{C}=\mathrm{O}$ and $\mathrm{C}-\mathrm{O}$ in oxalate ligands. The bands at 2960 and $1430 \mathrm{~cm}^{-1}$ are caused by the $\mathrm{C}-\mathrm{H}$ stretching and scissoring vibrations. The band at $3440 \mathrm{~cm}^{-1}$ is associated with the $\mathrm{N}-\mathrm{H}$ and $\mathrm{O}-\mathrm{H}$ stretching vibrations.

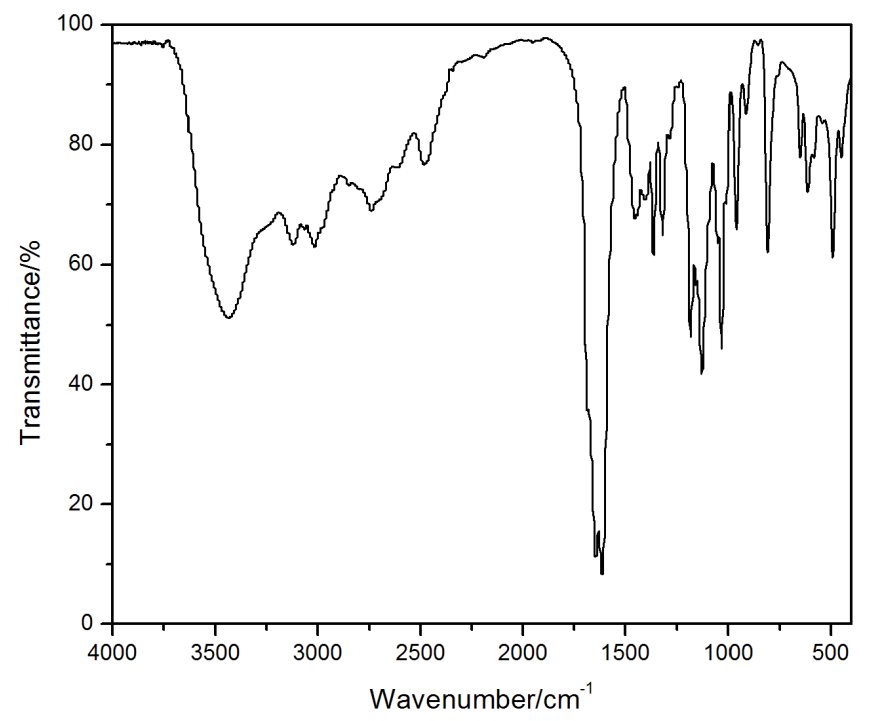

Figure S11. IR spectrum of compound 5. The peaks at $1610 \mathrm{~cm}^{-1}$ and $1320 \mathrm{~cm}^{-1}$ are attributed to the stretching vibrations of $\mathrm{C}=\mathrm{O}$ and $\mathrm{C}-\mathrm{O}$ in oxalate ligands. The intense bands between 1030-1180 $\mathrm{cm}^{-1}$ are associated with the stretching vibrations of $\mathrm{SO}_{4}$ groups. The bands at 1450 and $1360 \mathrm{~cm}^{-1}$ are caused by the $\mathrm{C}-\mathrm{H}$ scissoring and bending vibrations. 


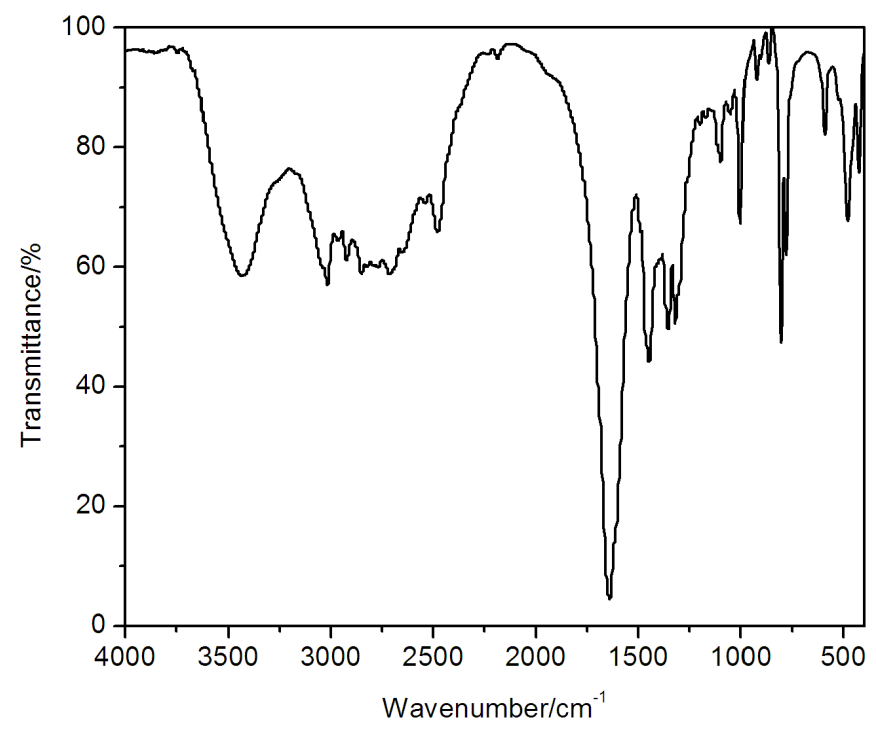

Figure S12. IR spectrum of compound 6. The peaks at $1640 \mathrm{~cm}^{-1}$ and $1320 \mathrm{~cm}^{-1}$ are attributed to the stretching vibrations of $\mathrm{C}=\mathrm{O}$ and $\mathrm{C}-\mathrm{O}$ in oxalate ligands. The bands at $3020,1450,1360 \mathrm{~cm}^{-1}$ are caused by the $\mathrm{C}-\mathrm{H}$ strethiing, scissoring, and bending vibrations. The band at $3430 \mathrm{~cm}^{-1}$ is associated with the $\mathrm{N}-\mathrm{H}$ stretching vibrations.

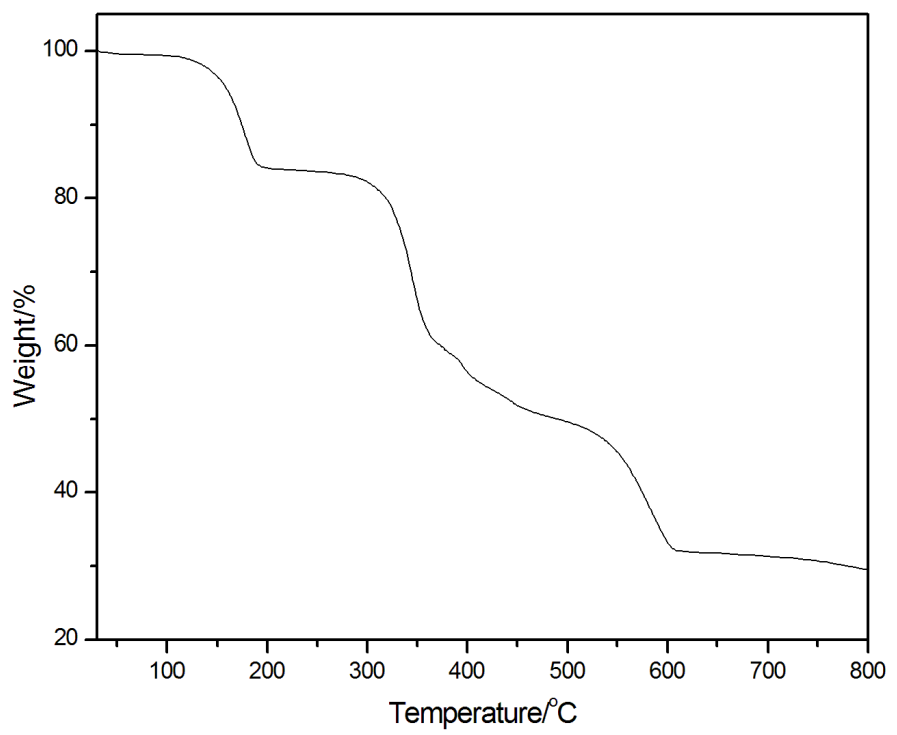

Figure S13. TGA curve of compound 1. The weight loss in the region $110-200{ }^{\circ} \mathrm{C}$ was attributed to the departure of water molecules (observed: $15.2 \%$, expected: $15.6 \%$ ). The weight loss in the region $280-610^{\circ} \mathrm{C}$ was attributed to the decomposition of amine molecules and oxalate ligands, and the loss of $\mathrm{SO}_{3}$. The remaining residue is assumed to be $\mathrm{ZnO}$ (observed: $29.5 \%$, expected: $30.3 \%$ ). 


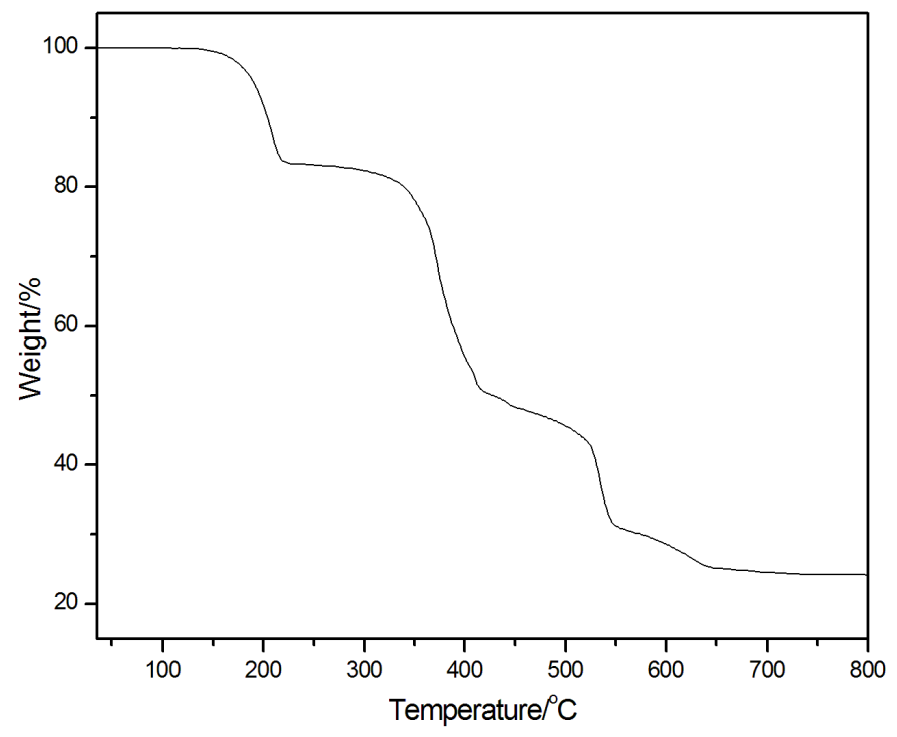

Figure S14. TGA curve of compound 2. Compound $\mathbf{2}$ displays a similar TGA curve as that of compound $\mathbf{1}$.

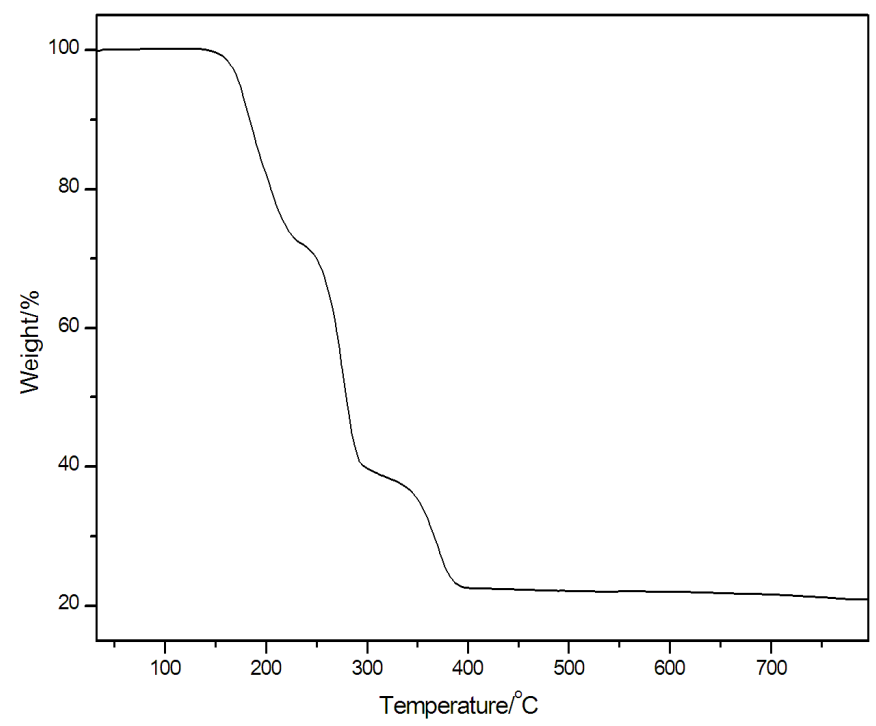

Figure S15. TGA curve of compound 3. The weight loss between $150-400{ }^{\circ} \mathrm{C}$ was attributed to the decomposition of amine molecules and oxalate ligands. Assuming that the final product is a mixture of $\mathrm{MnO}$ and $\mathrm{MnCO}_{3}$, the total weight loss of $77.4 \%$ is in agreement with the expected value of $78.7 \%$. 


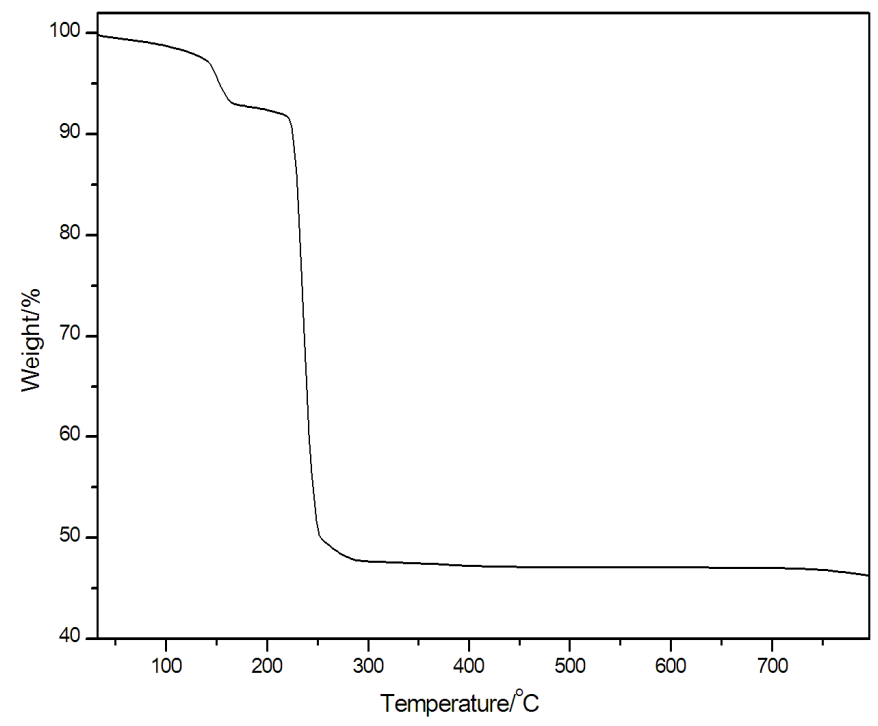

Figure S16. TGA curve of compound 4. There is a two-step weight loss below $300{ }^{\circ} \mathrm{C}$. The remaining residue is assumed to be Bi powder (observed: $46.2 \%$, expected: $45.1 \%$ ).

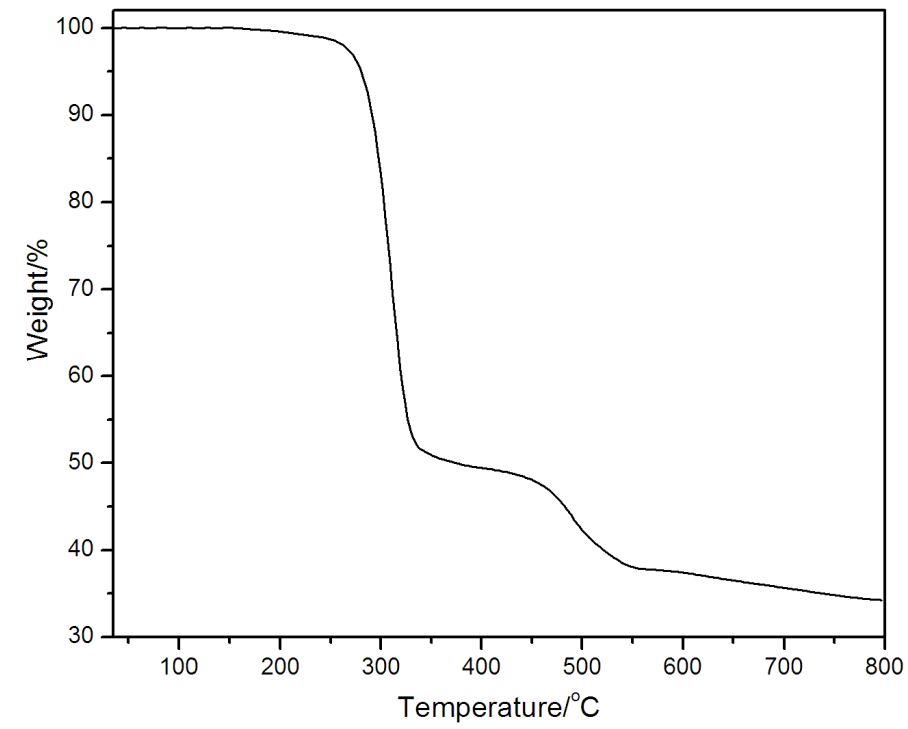

Figure S17. TGA curve of compound 5. The weight loss in the region $250-800{ }^{\circ} \mathrm{C}$ was attributed to the decomposition of amine molecules and oxalate ligands, and the loss of $\mathrm{SO}_{3}$. The remaining residue is assumed to be $\mathrm{In}_{2} \mathrm{O}_{3}$. However, the observed weight loss $(65.7 \%)$ was lower than the expected value $(69.8 \%)$. The lower reduction in this stage may be due to the partial loss of $\mathrm{SO}_{3}$. 


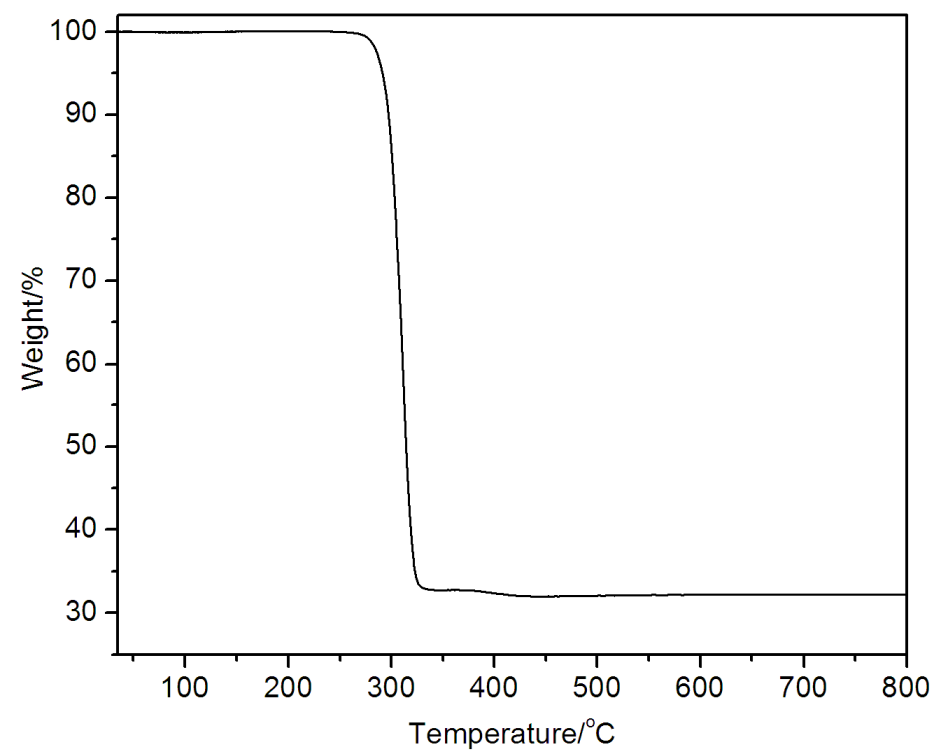

Figure S18. TGA curve of compound 6. The weight loss in the region $265-340{ }^{\circ} \mathrm{C}$ was attributed to the decomposition of amine molecules and oxalate ligand (observed: $67.2 \%$, expected: $69.2 \%$ ).

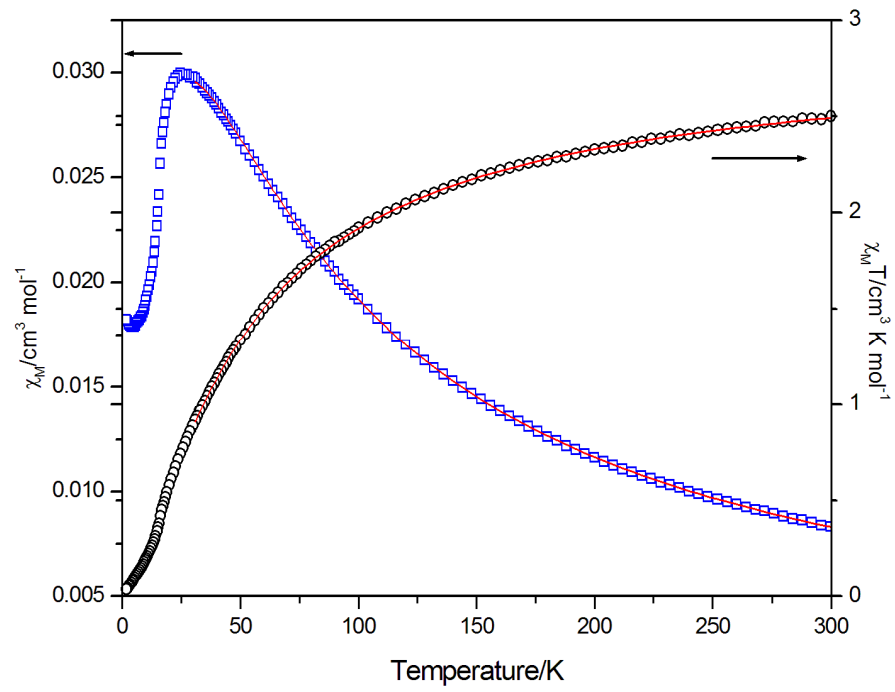

Figure S19. Temperature dependence of $\chi_{M}$ and $\chi_{M} T$ for compound 2. The red solid line represents the theoretical fits in the high-temperature region.

Considering the $1 \mathrm{D}$ equally spaced chain structures, the $\chi_{\mathrm{M}} T$ value of compound 2 can be fitted by Fisher's 1D Heisenberg chain model $\left(S=3 / 2, H=-2 J S_{i} S_{j}\right)$ expressed 
by the following equation: ${ }^{1-3}$

$$
\chi_{\text {chain }}=\frac{N g^{2} \beta^{2} S(S+1)}{3 k T} \frac{1+u}{1-u}
$$

where $u=\operatorname{coth}\left[\frac{2 J S(S+1)}{k T}\right]-\left[\frac{k T}{2 J S(S+1)}\right], J$ is the coupling constant of the neighboring $\mathrm{Co}^{2+}$ bridged by $\mathrm{C}_{2} \mathrm{O}_{4}{ }^{2-} . N, g, \beta, k$, and $T$ have their usual meanings. The interchain interaction termzj' at the mean field approximationis added to describe the inter-chains spin-spin interactions. ${ }^{4-5}$ Thus the expression for the magnetic susceptibility becomes

$$
\chi_{M}=\frac{\chi_{\text {chain }}}{1-\left(2 z j^{\prime} / N g^{2} \beta^{2}\right) \chi_{\text {chain }}}
$$

The best fitting parameters are $J=-10.04 \mathrm{~cm}^{-1}, \mathrm{zj}^{\prime}=-1.72 \mathrm{~cm}^{-1}, g=2.47$, and $R=$ $1.45 \times 10^{-3}$ for compound 2 ( $R$ is defined as $\left.\sum\left[\left(\chi_{M} T\right)_{o b s}-\left(\chi_{M} T\right)_{\text {calcd }}\right]^{2} / \sum\left[\left(\chi_{M} T\right)_{o b s}\right]^{2}\right)$.

\section{Reference:}

(1) Kahn, O. Molecular Magnetism; VCH: New York, 1993.

(2) Fisher, M. E. Am. J. Phys.1964, 32, 343.

(3) (a) Liu, T. F.; Fu, D.; Gao, S. J. Am. Chem. Soc. 2003, 125, 13976 . (b) Sun, H. L.; Wang, Z. M.; Gao, S. Chem. Eur. J. 2009, 15, 1757.

(4) (a) Myers, B. E.; Berger, L.; Friedberg, S. J. Appl. Phys. 1969, 40, 1149; (b) O’Connor, C. J. Prog. Inorg. Chem. 1982, 29, 203.

(5) (a) Carlin, R. L. Magnetochemistry; Springer: Heidelberg, 1986. (b) Carlin, R. L.; van Duyneveldt, A. J. Megnetic properties of Transition Metal Compounds; Springer: New York, 1977. 


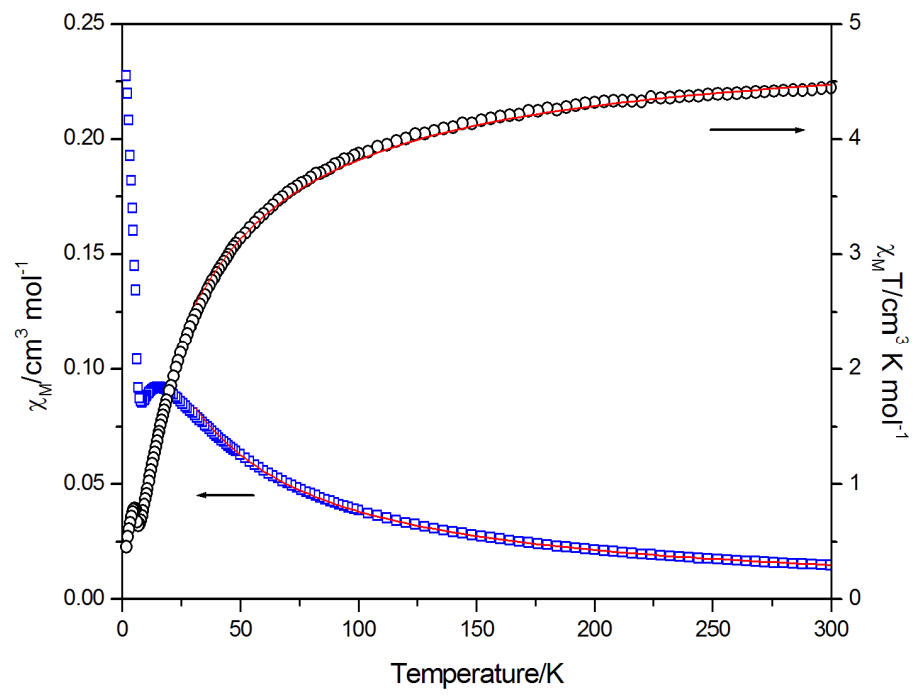

Figure S20. Temperature dependence of $\chi_{M}$ and $\chi_{M} T$ for compound 3. The red solid lines are fit to the Curie-Weiss law in the high-temperature region.

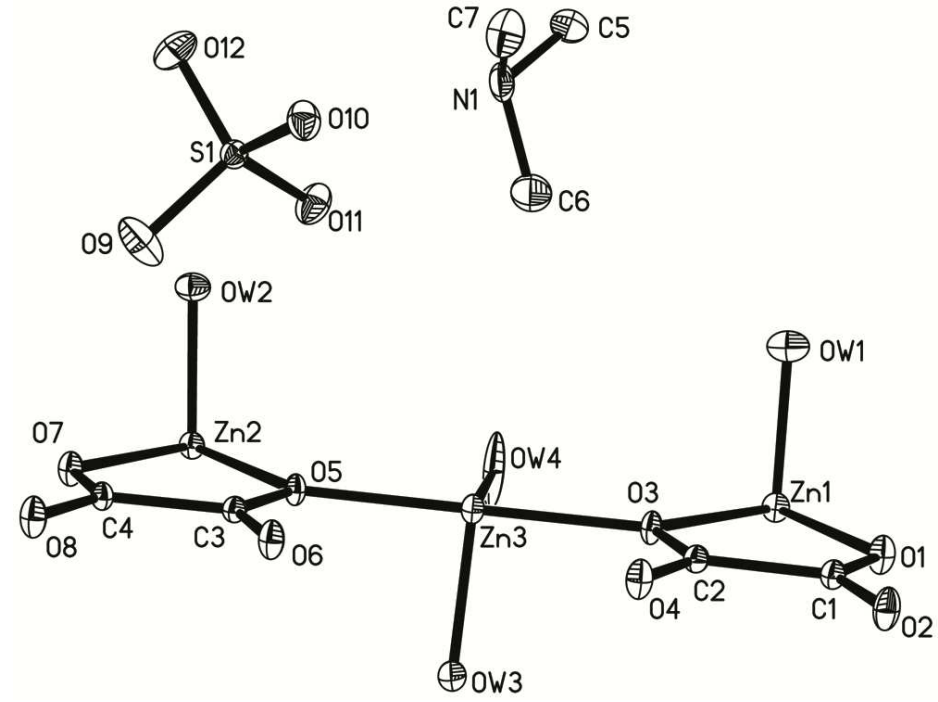

Figure S21. ORTEP plot of the asymmetric unit of compound 1, showing the labeling scheme and the $30 \%$ probability displacement ellipsoid. 


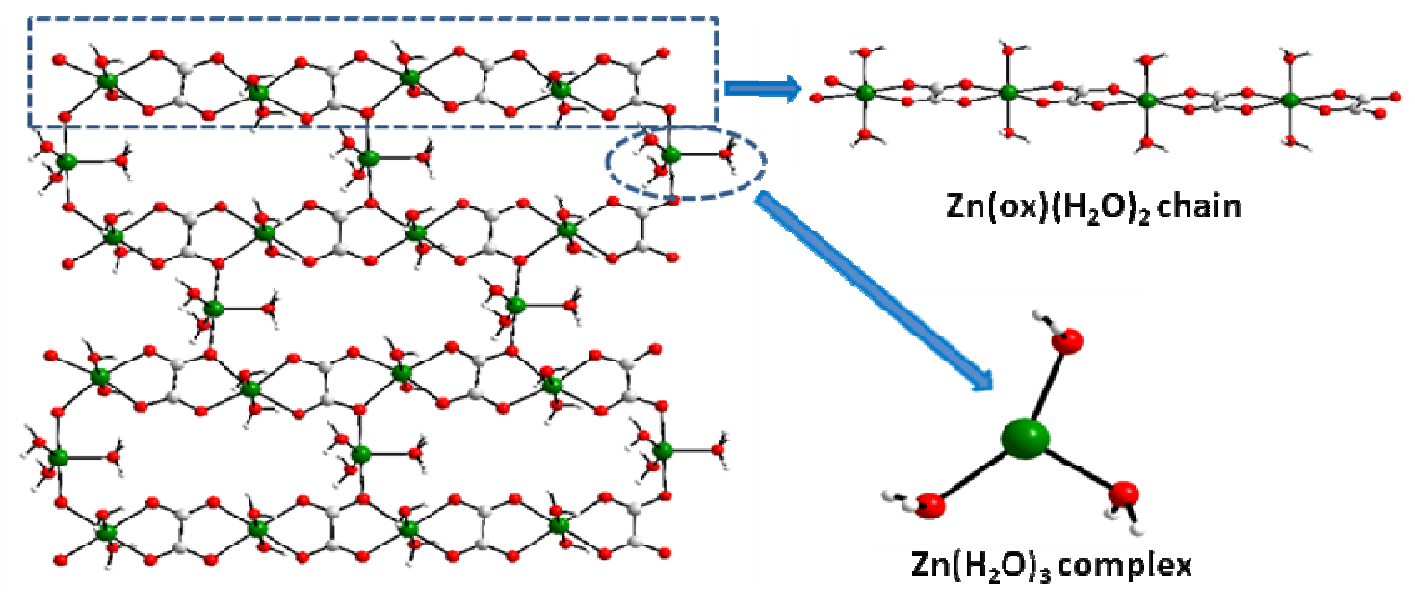

Figure S22. The layered structure of compound 1 constructed from $\mathrm{Zn}(\mathrm{ox})\left(\mathrm{H}_{2} \mathrm{O}\right)_{2}$ chains and $\mathrm{Zn}\left(\mathrm{H}_{2} \mathrm{O}\right)_{3}$ complexes.

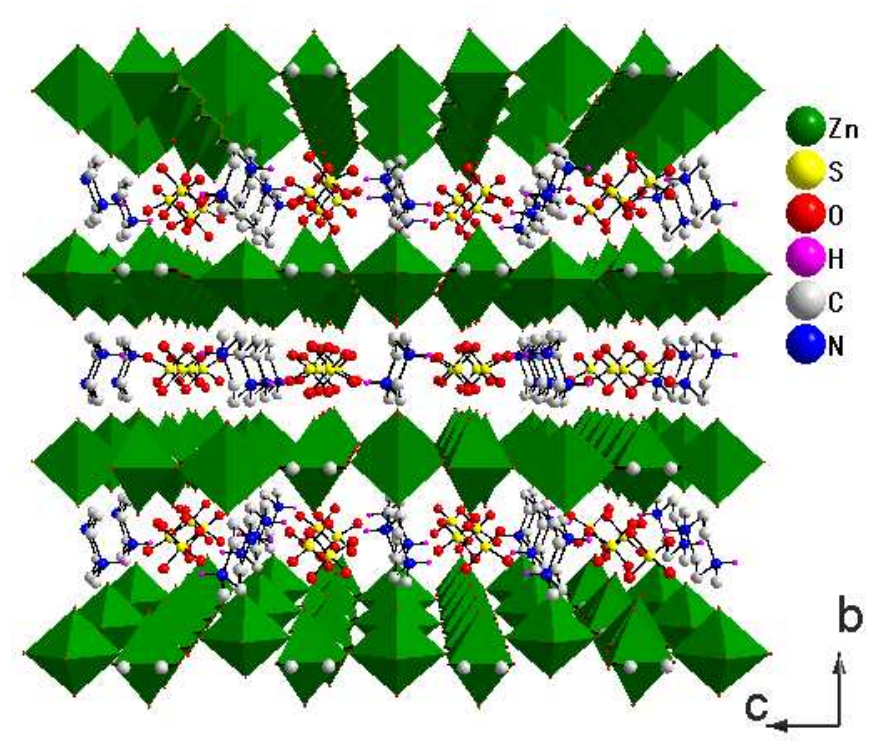

Figure S23. View of the structure of $\mathbf{1}$ along the [100] direction showing the zinc oxalate layers intercalated with supramolecular templates. 


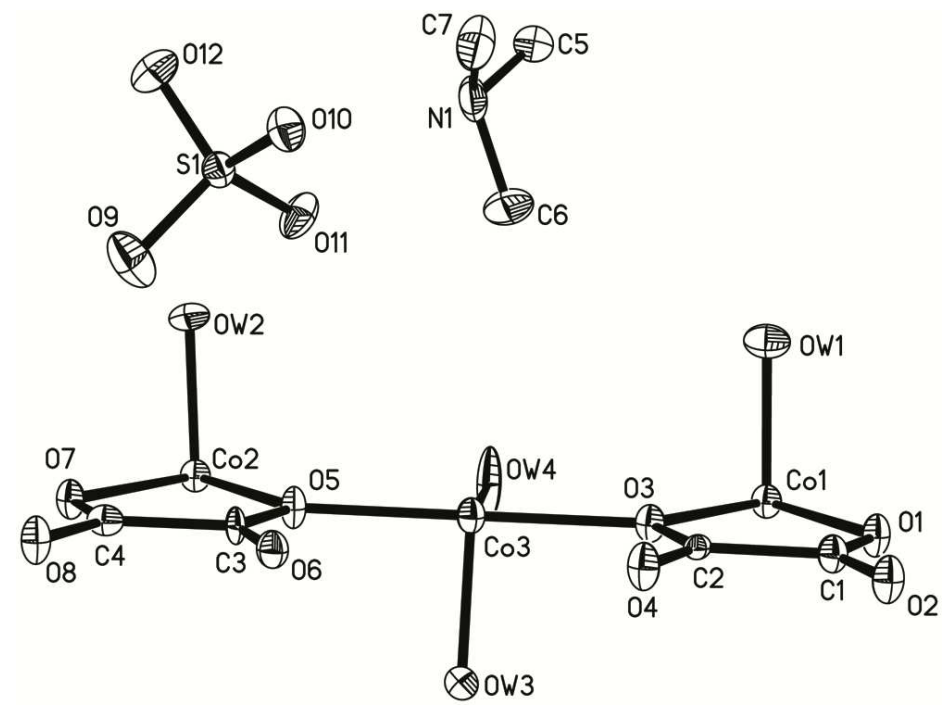

Figure S24. ORTEP plot of the asymmetric unit of compound 2, showing the labeling scheme and the $30 \%$ probability displacement ellipsoid.

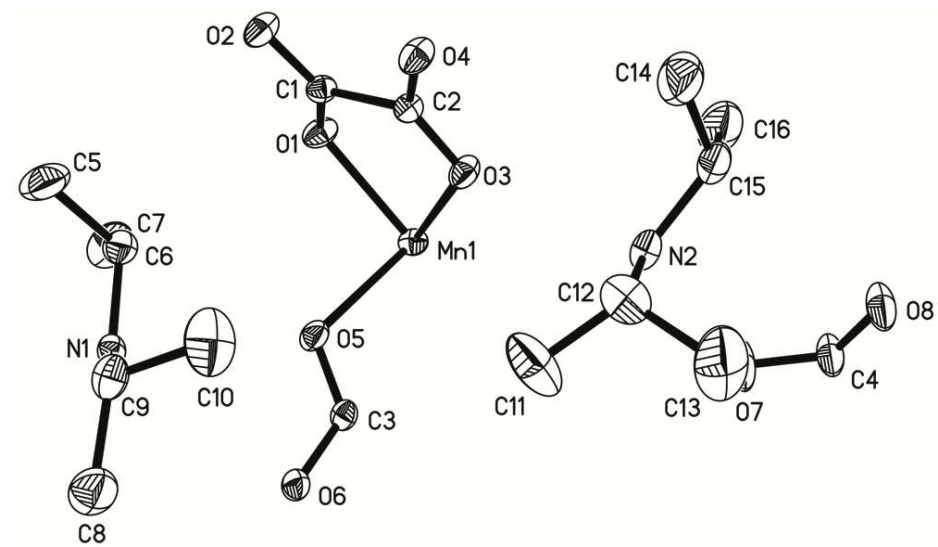

Figure S25. ORTEP plot of the asymmetric unit of compound 3, showing the labeling scheme and the $30 \%$ probability displacement ellipsoid. 


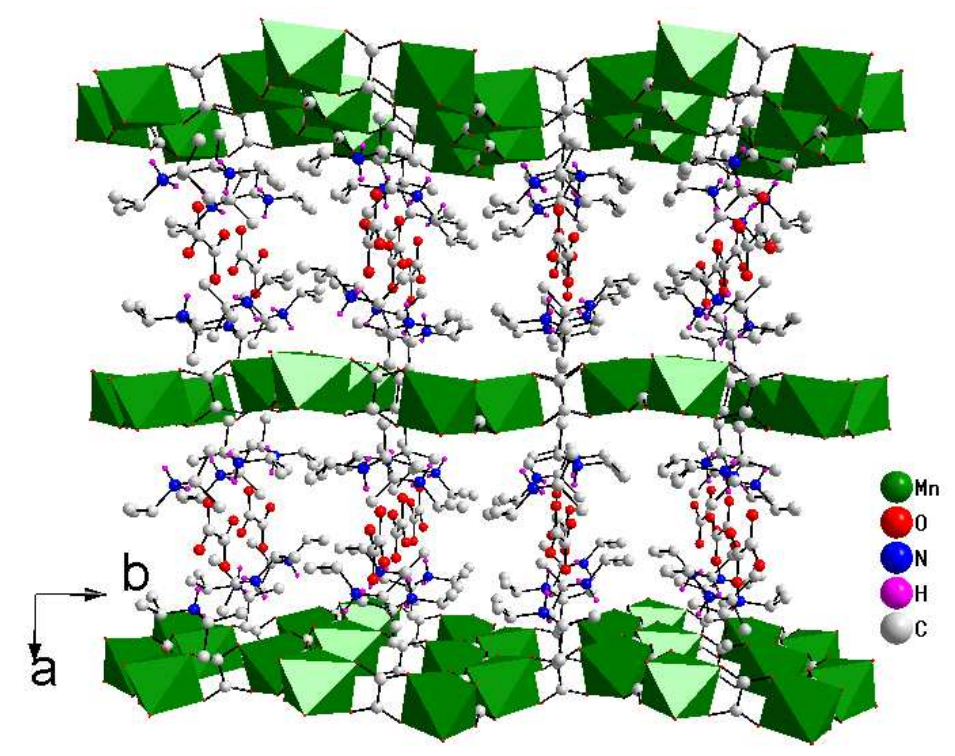

Figure S26. View of the structure of $\mathbf{3}$ along the [001] direction showing the manganese oxalate layers intercalated with supramolecular templates.

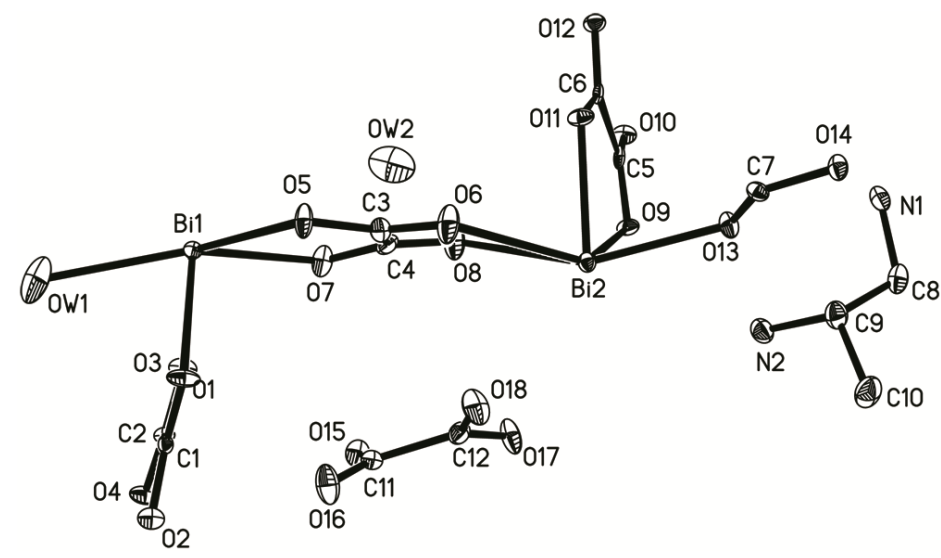

Figure S27. ORTEP plot of the asymmetric unit of compound 4, showing the labeling scheme and the $30 \%$ probability displacement ellipsoid. 


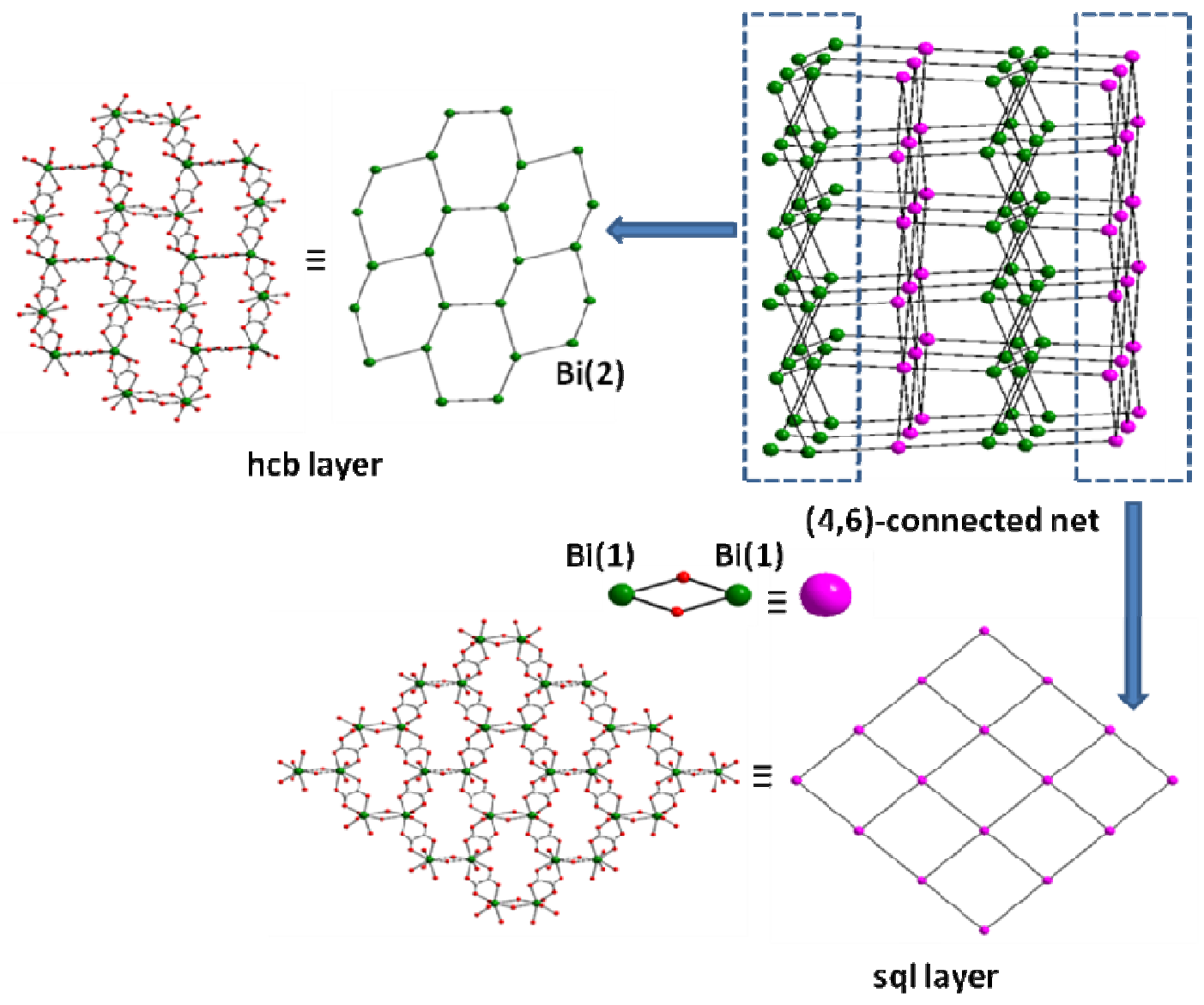

Figure S28. A view of the (4,6)-connected network of $\mathbf{4}$ constructed from hcb layers and sql layers.

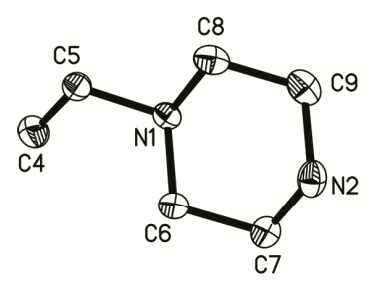

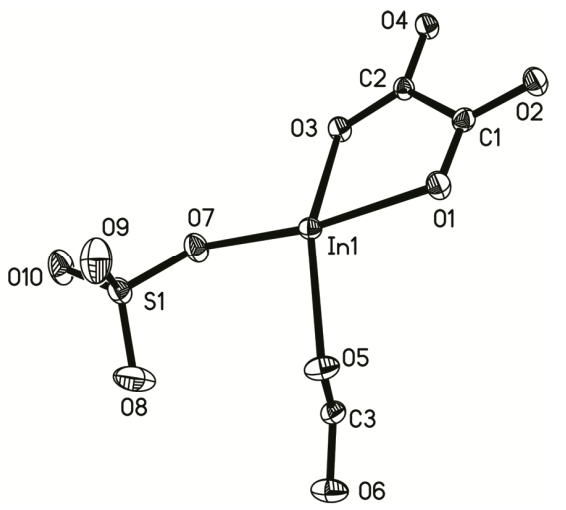

Figure S29. ORTEP plot of the asymmetric unit of compound 5, showing the labeling scheme and the $30 \%$ probability displacement ellipsoid. 


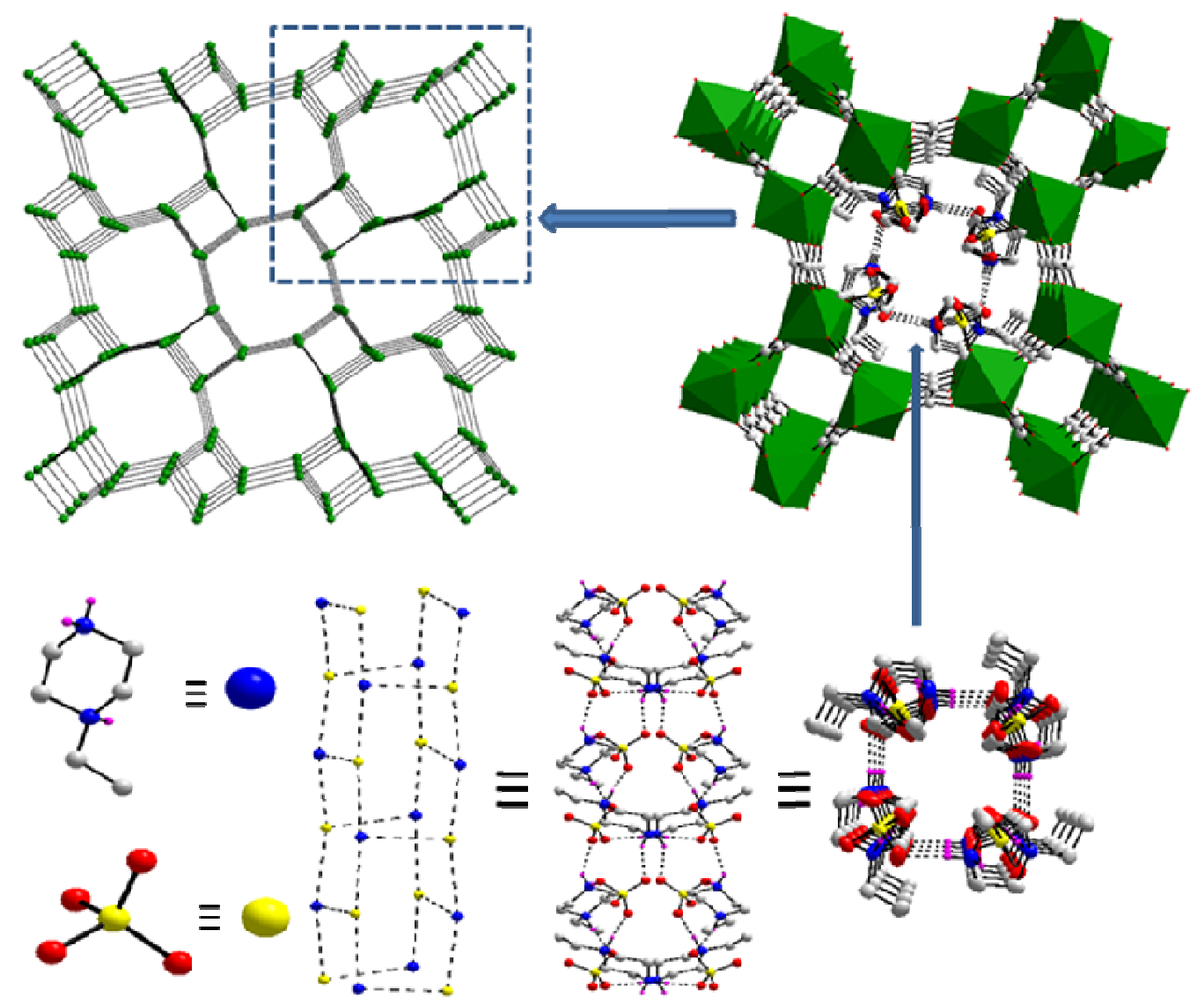

Figure S30. A view of the 3-connected lig network of 5 showing the column-like supramolecular templates within 16 MR channels.

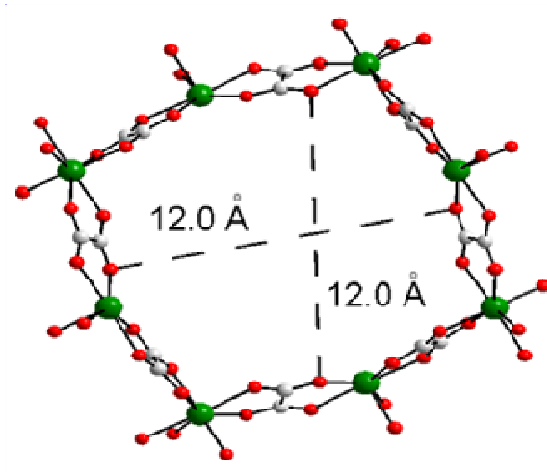

$16 \mathrm{MR}$

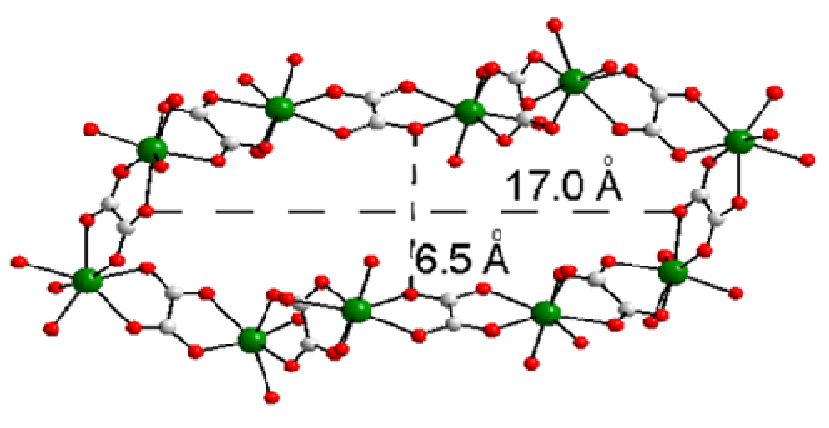

$20 \mathrm{MR}$

Figure S31. The $16 \mathrm{MR}$ and $20 \mathrm{MR}$ windows in compound 5. 

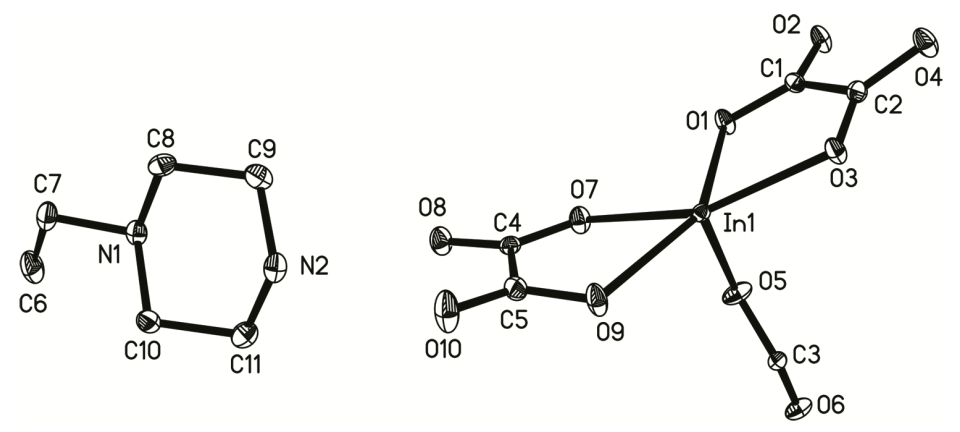

Figure S32. ORTEP plot of the asymmetric unit of compound 6, showing the labeling scheme and the $30 \%$ probability displacement ellipsoid.

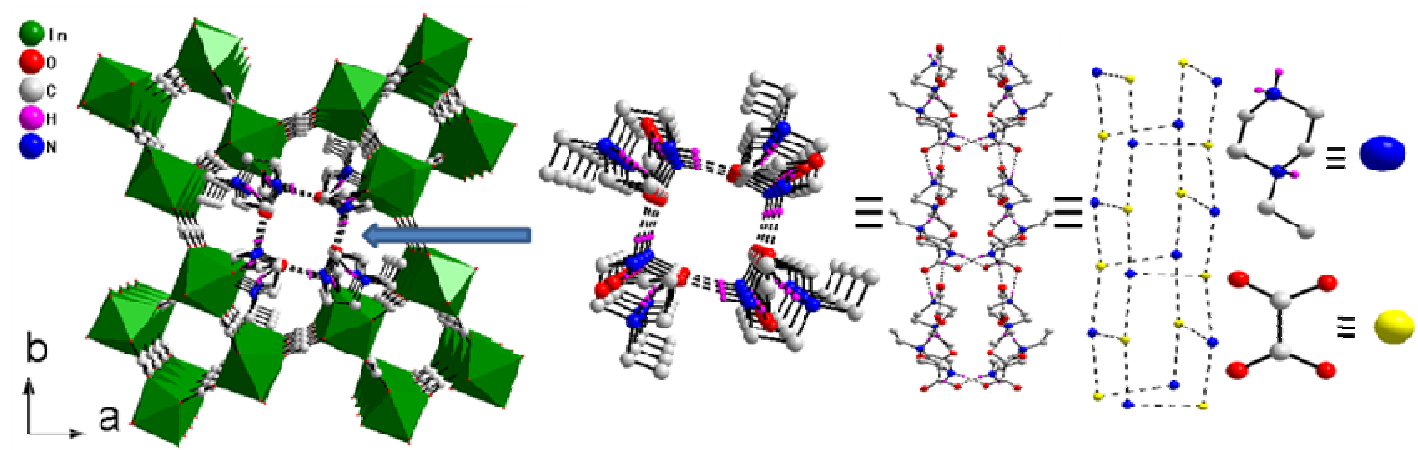

Figure S33. A view of the framework structure of $\mathbf{6}$ showing the column-like supramolecular templates within $16 \mathrm{MR}$ channels. 